\title{
Association between Metabolic Syndrome(Mets) and Physical Function in Community-Dwelling Older Women in Korea
}

\author{
Seung youn Hong* \\ Department of Senior Industry, Kangnam University,South Korea
}

Received: April 03, 2018; Published: April 23, 2018

*Corresponding author: Seung youn Hong, Dept of Senior Industry, Kangnam University, Yongin, South Korea, Tel: 81-10-8799-4185; Email: Yoni91@hotmail.com

Abstract

Background: Metabolic Syndrome (MetS) is a complex disorder unifying dyslipidemia, insulin resistance, and hypertension. MetS has been well known as a primary risk factor for diabetes and cardiovascular disease. The loss of muscle mass and strength with age is also significantly associated with type II diabetes and cardiovascular disease in older adults. Although these two phenomena seem to be associated with each other, little is known concerning the relationship between MetS and body composition status as well as physical function specific to Korean older women, who have a higher incidence of cardiovascular disease and type Ii diabetes and also have lowered physical function. The purpose of this study was to determine whether there is a relationship between Metabolic syndrome and body composition \& physical function in older women in Korea.

Method: The overall prevalence of metabolic syndrome in these participants was $42.5 \%$. Systolic $(t=2.14, p<.05)$ and diastolic blood pressure $(t=2.85, p<.01)$ were significantly higher in MetS than Non-Mets. MetS also has higher fat $(t=2.14, p<.05)$, percent fat $(t=2.85$, $p<.01)$, BMI ( $t=2.49, \mathrm{p}<.05)$, waist circumference $(t=2.73, \mathrm{p}<.01)$ than non-MetS. Different from our expectation, there were no difference in 30-second chair stand, arm curl and sit and reach. However, older women without metabolic syndrome had better balance, agility \& dynamic balance, aerobic endurance $(\mathrm{p}<.05)$ than women with MetS.

Results: The overall prevalence of metabolic syndrome in these participants was $42.5 \%$. Systolic $(\mathrm{t}=2.14, \mathrm{p}<.05)$ and diastolic blood pressure $(t=2.85, p<.01)$ were significantly higher in MetS than Non-Mets. MetS also has higher fat $(t=2.14, p<.05)$, percent fat $(t=2.85$, $p<.01)$, BMI ( $t=2.49, \mathrm{p}<.05)$, waist circumference $(\mathrm{t}=2.73, \mathrm{p}<.01)$ than non-MetS. Different from our expectation, there were no difference in any physical function measures (i.e., 30-second chair stand, arm curl, sit and reach, one-leg stand, 244 Time to Up and Go, 2-minute steps) between MetS and non-MetS.In the further analysis by obese category, there were significant differences observed on BMI ( $\mathrm{z}=-3.984, \mathrm{p}<.001)$, body fat ( $\mathrm{z}=-2.37$, $\mathrm{p}<.05)$ and percent body fat $(\mathrm{z}=-3.08, \mathrm{p}<.01)$ only in normal weight group. No difference of any above variables between MetS and non-MetS in overweight and obese groups has been observed. In physical function, only char stand in obese group were significantly different between MetS and non-MetS $(\mathrm{z}=-2.62, \mathrm{p}<.01)$

Conclusion: In conclusion, metabolic syndrome in older women may worsen physical function. Understanding the current distribution of MetS and its relation with physical function in older adults may help to customize clinical and public health initiatives aimed at reducing disability in older women. Feature of metabolic syndromes were significantly associated metabolic syndrome yet there were not clear relationship between MetS and physical function in older adults. Further investigation is needed to figure out whether MetS affect physical function and disability status in later life.

Keywords: Metabolic Syndrome; Physical Function; Older

Abbreviations: MetS: Metabolic Syndrome; HDL: High Density Lipoprotein; BMI: Body Mass Index; SFT: Senior Fitness Test

\section{Introduction}

Decreased functional capacity in older adults will be a major public concern in most countries. It is of significant public health importance to be able to predict decline in functional status, and loss of personal independence, especially decline in mobility, because problems with mobility typically arise before decline in instrumental and basic activities of daily living. Understanding characteristics of older people caused to functional problem may facilitate intervention strategies that may slow the rate of further functional decline. 
Metabolic syndromes (Mets) have been related not only to presence of multiple chronic diseases but also to the development of disability. With the increased rate and growing expense of Mets [1], and greater probability of exposing this into older population, understanding the relationship between metabolic syndrome and functional decline in older adults is critical issue. This is important because it suggests that there may be a link between the mechanical and metabolic functions of ageing muscle. The mechanism is unclear, but aged muscle and insulin-resistant states share common cellular and molecular changes [2,3,4].Previous studies reported the inverse associations between metabolic syndrome and physical function[5-8]. The impact of metabolic syndrome in functional capacity of older population is not established, however. The purpose of this study was to examine the effect of metabolic syndrome on physical function in Korean older women. We hypothesized that older women with metabolic syndrome would have lower score of physical function than one without metabolic syndrome.

\section{Materials and Methods}

\section{Subjects}

Table 1: Characteristics of the study population $(n=275)$.

\begin{tabular}{|c|c|}
\hline Variable & $\mathrm{n}(\%)$ or $\mathrm{M} \pm \mathrm{SD}$ \\
\hline Age(years) & $74.24 \pm 8.58$ \\
\hline Weight(kg) & $57.90 \pm 8.69$ \\
\hline Height $(\mathrm{cm})$ & $149.88 \pm 5.89$ \\
\hline Body Mass Index(kg/m2) & $25.72 \pm 3.29$ \\
\hline Fat mass(kg) & $21.80 \pm 5.84$ \\
\hline Fat Free mass (kg) & $36.75 \pm 4.42$ \\
\hline Percent Fat $(\%)$ & $36.08 \pm 5.93$ \\
\hline $\begin{array}{l}\text { Education } \mathrm{n}(\%) \\
\text { None } \\
\text { Elementary school } \\
\text { Middle school } \\
\text { Highs school } \\
\text { over College }\end{array}$ & $\begin{array}{c}100(36.4) \\
109(39.7) \\
35(12.8) \\
25(9.1) \\
6(2.1)\end{array}$ \\
\hline $\begin{array}{c}\text { Marital status } \mathrm{n}(\%) \\
\text { married/live with spouse } \\
\text { widowed } \\
\text { live separate } \\
\text { Never Married } \\
\text { Etc }\end{array}$ & $\begin{array}{c}74(27) \\
183(66.4) \\
8(2.9) \\
6(2.1) \\
5(1.7)\end{array}$ \\
\hline $\begin{array}{c}\text { Chronic conditions n(\%) } \\
\text { Arthritis } \\
\text { Hypertension } \\
\text { Diabetes } \\
\text { Stroke } \\
\text { Liver disease } \\
\text { High triglyceride }\end{array}$ & $\begin{array}{c}170(61.9) \\
177(64.3) \\
63(23) \\
23(8.3) \\
17(6.3) \\
81(29.4)\end{array}$ \\
\hline
\end{tabular}

\begin{tabular}{|c|c|}
\hline Perceived Health $\mathrm{n}(\%)$ & $26(9.3)$ \\
very poor & $78(28.5)$ \\
poor & $93(33.7)$ \\
Fair & $67(24.4)$ \\
Good & $11(4.1)$ \\
very good & \\
\hline
\end{tabular}

Data were collected on body composition, blood pressure, waist circumference and fasting glucose, triglyceride in 275 communitydwelling older women aged 60-95 years. The characteristics of the study population are presented in (Table 1). Of the study participants, 116 women were classified in metabolic syndrome. Accounting for all the participants, the mean age was 74 years, and mean BMI was $25.7 \mathrm{~kg} / \mathrm{m} 2$. More than $66 \%$ of women were widow and $76.1 \%$ of participants had $\leq 6$ years of education. Additionally $61.9 \%$ of women had arthritis and $64 \%$ of women had hypertension (Table 1).

\section{Definition of the metabolic syndrome}

The definition of the metabolic syndrome proposed by the NCEP ATP III(National Heart Lung and Blood Institute, 2001) was applied for this study. As detailed in the NCEP ATP III report, participants having three or more of the five following criteria were defined as having the metabolic syndrome: high blood pressure $(\geq 130 / \geq 85 \mathrm{mmHg}$ ), elevated fasting blood glucose $(\geq 110 \mathrm{mg} /$ $\mathrm{dl}$ or $\geq 6.05 \mathrm{mmol} / \mathrm{l}$ ), hypertriglyceridemia ( $\geq 150 \mathrm{mg} / \mathrm{dl}$ or $\geq 1.65$ $\mathrm{mmol} / \mathrm{l}$ ), low high density lipoprotein (HDL)-cholesterol (men, $<40$ $\mathrm{mg} / \mathrm{dl}$ or $<1.05 \mathrm{mmol} / \mathrm{l}$; women, $<50 \mathrm{mg} / \mathrm{dl}$ or $<1.30 \mathrm{mmol} / \mathrm{l}$ ), and abdominal obesity, as measured by a waist circumference of $>102$ $\mathrm{cm}$ for men and $>88 \mathrm{~cm}$ for women.

\section{Anthropometric measurements}

Participants' height was measure to the nearest $0.1 \mathrm{~cm}$. Weight was measure in the upright position to the nearest $0.1 \mathrm{~kg}$. Body Mass Index (BMI) was calculated by dividing weight (kg) by height squared(m2). Waist circumference measurements were taken at the end of normal expiration to the nearest $0.1 \mathrm{~cm}$, measuring from the narrowest point between the lower borders of the rib cage and the iliac crest.

\section{Cardiovascular risk factors}

The blood pressure of each subjects in the sitting position after 10-minute rest period using TM-2655P (Biospace 720, Korea). Two readings, each of systolic and diastolic blood pressure were recorded and the average of each measurement was used for data analysis.

\section{Physical Function}

Participants proceeded to complete the Senior Fitness Test (SFT) items. The SFT utilized in this study consisted of 5 different assessments: chair stand to assess lower body strength, arm curl to assess upper body strength, 2-minute step to assess aerobic endurance, chair sit- and-reach to assess lower body flexibility, back scratch to assess upper body flexibility, and the 8-foot up-andgo to assess the agility and dynamic balance(Table 2). 
Table 2: Brief Description of Senior Fitness Test Items.

\begin{tabular}{|c|c|c|}
\hline Test Item & Category & Description \\
\hline Chair stand & Lower body strength & Number of full stands in 30 seconds with arm folded across chest \\
\hline Arm curl & Upper body strength & Number of biceps curls in 30 seconds holding had weight(Women 2kg) \\
\hline Two-minute step & Aerobic endurance & $\begin{array}{c}\text { Number of full steps completed in 2-minutes, raising each knee to midway } \\
\text { between patella and iliac crest }\end{array}$ \\
\hline Chair sit-and-reach & Lower body flexibility & $\begin{array}{c}\text { From sitting position at from of chair, with leg extended and hands reaching } \\
\text { toward toes }\end{array}$ \\
\hline $244 \mathrm{~cm}$ Time to up-and-go(TUG) & Agility/dynamic balance & $\begin{array}{c}\text { Number of seconds required to rise from seated position, walk 8 feet(244cm), } \\
\text { turn and return to seated position on chair }\end{array}$ \\
\hline \multicolumn{2}{|c|}{ * Full test description can be found in Rikli and Jones(Rikli \& Jones, 2001) } \\
\hline
\end{tabular}

\section{Data Analysis}

Unpaired t-test, univariate analysis, and chi-square test were used to assess whether differences in the clinical characteristics existed between the older women with and without metabolic syndrome. All analyses were performed using the SPSS-PC (SPSS Inc, Chicago, IL) statistical package. Statistics significance was set at $\mathrm{P}<.05$. Measurements are presented as mean \pm standard deviations.

\section{Results}

General characteristics of study populationTwo hundred seventy-five older women (mean age of 74.24 (60-95)) participated in the assessments over the testing period. The overall prevalence of metabolic syndrome in participants was $42.5 \%$. The characteristics of the study group are displayed in (Table 3). The clinical characteristics of the older women with and without metabolic syndrome are presented in (Table 2). As expected, women with metabolic syndrome had a higher prevalence $(p<.05)$ of each characteristic of metabolic syndrome (diabetes, high BMI) than those without metabolic syndrome. However, the two groups were similar in age, height, and weight.As summarized in (Table 4), women with metabolic syndrome also had higher percent body fat $(\mathrm{p}<.01)$, higher waist circumference $(\mathrm{p}<.01)$ and higher systolic $(\mathrm{p}<.01]$ and diastolic blood pressure $(\mathrm{p}<.05)$ (Table 4).The association between metabolic syndrome and physical function is shown in Table 5. Different from our expectation, there were no differences in chair stand, arm-curl, sit and reach between older women with and without metabolic syndrome. However, Older women without metabolic syndrome had better balance -- more extended one-leg stand $(\mathrm{p}<.01)$, better agility \& dynamic balance --shorter 244 TUG $(\mathrm{p}<.05)$ and better aerobic endurance --higher 2-minute steps $(\mathrm{p}<.05)$ than women without the Metabolic syndrome (Table 5).

Table 3: Clinical characteristic of elderly women with and without metabolic syndrome.

\begin{tabular}{|c|c|c|}
\hline Variables & $\begin{array}{c}\text { Mets(n=116) } \\
\text { Mean } \pm \text { SD or } \mathbf{n}(\%)\end{array}$ & $\begin{array}{c}\text { Non-Mets(=133) } \\
\text { Mean } \pm \text { SD or } \mathbf{n}(\%)\end{array}$ \\
\hline Age(years) & $74.67 \pm 7.98$ & $73.93 \pm 7.28$ \\
\hline Weight(kg) & $58.89 \pm 7.71$ & $57.03 \pm 9.40$ \\
\hline Height & $149.51 \pm 5.96$ & $150.21 \pm 5.83$ \\
\hline $\begin{array}{c}\text { Body Mass Index(kg/ } \\
\text { m2) }\end{array}$ & $26.27 \pm 2.71$ & $25.24 \pm 3.67^{*}$ \\
\hline Arthritis & $74(63.79)$ & $82(61.65)$ \\
\hline Diabetes & $38(32.76)$ & $20(15.04) * *$ \\
\hline Hypertr & $93(80.17)$ & $79(59.40)$ \\
\hline Hyperlipidemia & $32(27.59)$ & $42(31.58)$ \\
\hline \multicolumn{3}{|c|}{$* \mathrm{p}<.05, * * \mathrm{p}<.001$} \\
\hline
\end{tabular}

Table 4: Characteristics of body composition with and without MetS.

\begin{tabular}{|c|c|c|c|c|c|c|}
\hline & Fat & \% fat & waist & WHR & SBP & DBP \\
\hline MetS(n=116) & $22.65 \pm 5.07$ & $37.21 \pm 5.09$ & $93.98 \pm 8.20$ & $0.95 \pm 0.07$ & $135.77 \pm 15.22$ & $77.09 \pm 11.25$ \\
\hline Non-MetS $(\mathrm{n}=133)$ & $21.06 \pm 6.37^{*}$ & $35.08 \pm 6.44^{* *}$ & $90.70 \pm 10.30^{* *}$ & $0.93 \pm 0.08$ & $127.20 \pm 15.35^{* * *}$ & $73.59 \pm 11.34^{*}$ \\
\hline
\end{tabular}

MetS: with Metabolic syndrome, Non-MetS: without Metabolic syndrome*: < $^{*} .05,{ }^{* *} ; \mathrm{p}<.01$, ***: ${ }^{*}<.001$

Table 5: Characteristics of physical function with and without MetS.

\begin{tabular}{|c|c|c|c|c|c|c|}
\hline & Chair stand (times) & Arm curl (times) & Sit and reach (cm) & One leg stand (sec) & 244TUG (sec) & 2 min steps (times) \\
\hline MetS(n=116) & $14.84 \pm 4.69$ & $19.97 \pm 5.62$ & $11.08 \pm 7.94$ & $12.20 \pm 15.42$ & $7.65 \pm 2.15$ & $91.38 \pm 29.65$ \\
\hline Non-MetS(n=133) & $15.68 \pm 4.94$ & $21.10 \pm 5.83$ & 12.067 .85 & $14.72 \pm 16.17^{* *}$ & $7.44 \pm 2.22^{*}$ & $92.86 \pm 30.83^{*}$ \\
\hline
\end{tabular}

244TUG: $244 \mathrm{~cm}$ time to up and go test; *: $\mathrm{p}<.05$, **; $\mathrm{p}<.01$

\section{Discussion}

This study offers two main findings. First, Mets was highly prevalent in this sample of adults age 70 and older women at high risk of physical limitation. Second, MetS may worsen physical function in this population. Older women who had MetS had the lower level of balance, agility \& dynamic balance, and aerobic endurance than women without metabolic syndrome. This result is consistent with previous research that patients with Mets 
had lower peak oxygen uptake and a shorter 6-minute walk distance $[5,6,9]$. This can be explained that the loss of muscle mass and strength combined with the gain in abdominal fat may act synergistically to exacerbate metabolic disorders and increased chance of disability[10-12]. Given these considerations, it would be expected that metabolic syndrome would predict a decline in mobility over time. Furthermore, it is intuitive that having high levels of fat mass together with low muscle mass may lead to more functional limitations, as well as to more metabolic disorders[13] Previous research reported that physical inactivity, obesity, and diet composition appear to be risk factors for the development of the metabolic syndrome. Several studies have shown that the effectiveness of regular physical activities such as resistance and aerobic training in reducing cardiovascular risk in older women $[14,15]$. Further, structure PA prevents from mobility disability and Metabolic syndrome in older adults with functional limitation $[16,17]$ reported elastic band training produced improvements in both metabolic parameters and functional fitness. Also, reported that moderate- to high-intensity aerobic exercise produced improvements in insulin sensitivity, triglyceride and low-density lipoprotein cholesterol in sedentary obese adults. These findings suggest that variation in exercise training might help to maximize physical adaptations.

Not only physical activity but also diet has been reported that's inverse association with Mets [18] reported that a Mediterraneanstyle intake was inversely associated with the cumulative incidence of MetS. Further, Mediterranean diet improves physical domain of health-related quality of life and lowers the odds of LDL-C [19] TGs, and low HDL-C levels [20-23]. Therefore, future research needs to further analyze controlling diet and physical activity factors to investigate the association between physical function and Mets. There are several study limitations that must be addressed. A longer intervention might have allowed for the investigation of significant differences between seniors with Mets and without Mets. In addition, intervention studies are necessary to establish dose-dependent relationships of PA and physical function in elders with Mets.

\section{Conclusion}

Metabolic syndrome may worsen physical function in older women. Older women with MetS have the lower level of several functional capacities such as static balance, agility \& dynamic balance and aerobic endurance than older women without MetS.

\section{References}

1. Joongang (2010) Medical expenditure for MetS were about 565 million dollars in Korea in 2010.

2. Furler SM, Poynten AM, Kriketos AD, Lowy AJ, Ellis BA, et al. (2001) Independent influences of central fat and skeletal muscle lipids on insulin sensitivity. Obes Res 9(9): 535-543.

3. JanssenI, RossR (2005) Linking age-related changes in skeletal muscle mass and composition with metabolism and disease. J Nutr Health Aging 9(6): 408-419.

4. Shulman GI (2000)Cellular mechanisms of insulin resistance. J Clin Invest 106(2): 171-176.
5. Gardner AW, Montgomery PS, Parker DE (2006) Metabolic syndrome impairs physical function, health-related quality of life, and peripheral circulation in patients with intermittent claudication. J Vasc Surg. 43(6): 1191-1196.

6. Gardner AW, Montgomery PS,Parker DE (2006) "Metabolic syndrome impairs physical function, health-related quality of life, and peripheral circulation in patients with intermittent claudication." Journal of vascular surgery 43(6): 1191-1196.

7. Jurca R, Lamonte MJ, Church TS, Earnest CP, Fitzgerald SJ, et al. (2004) Associations of muscle strength and fitness with metabolic syndrome in men. Med Sci Sports Exerc 36(8):1301-1307.

8. Jurca R, Lamonte MJ, Church TS, EarnestCP, Fitzgerald SJ(2004) Associations of Muscle Strength and Aerobic Fitness with Metabolic Syndrome in Men Med Sci. Sports Exerc 36(8): 1301-1307.

9. Botoseneanu A, Chen H, Ambrosius WT, Allore HG, Anton S, et al. (2017) Effect of Metabolic Syndrome on the Mobility Benefit of a Structured Physical Activity Intervention-The Lifestyle Interventions and Independence for Elders Randomized Clinical Trial. Journal of the American Geriatrics Society 65(6): 1244-1250.

10. Baumgartner R (2000) Body composition in healthy aging. Annals of the New York Academy of Sciences 904(1): 437-448.

11. Baumgartner RN, Wayne SJ, Waters DL, Janssen I, Gallagher D, et al. (2004) Sarcopenic obesity predicts instrumental activities of daily living disability in the elderly. Obes Res 12(12): 1995-2004.

12.Zamboni M, Turcato E, Santana H, Maggi S, Harris TB, et al. (1999) The relationship between body composition and physical performance in older women. J Am Geriatr Soc47(12): 1403-1408.

13. Janssen I (2006) Influence of sarcopenia on the development of physical disability: the Cardiovascular Health Study. J Am Geriatr Soc 54(1): 5662.

14. Colado J, Garcia-Masso X,Rogers ME, Tella V, Benavent J, et al. (2012) Effects of aquatic and dry land resistance training devices on body composition and physical capacity in postmenopausal women. Journal of human kinetics 32: 185-195.

15. Martins WR, Safons MP,Martim Bottaro, Juscelino Castro Blasczyk, Leonardo Rios Diniz, et al. (2015) Effects of short term elastic resistance training on muscle mass and strength in untrained older adults: a randomized clinical trial. BMC geriatrics 15: 99.

16. Pahor M, Guralnik JM, Ambrosius WT, Blair S, Bonds DE, et al. (2014) Effect of structured physical activity on prevention of major mobility disability in older adults: the LIFE study randomized clinical trial. Jama 311(23): 2387-2396.

17. FlandezJ, Belando N, Gargallo P, Fernández-Garrido J, Vargas-Foitzick RAet al. (2017) Metabolic and functional profile of premenopausal women with metabolic syndrome after training with elastics as compared to free weights. Biological research for nursing 19(2): 190197.

18. Landaeta-Díaz L, Fernández J, Da Silva-Grigoletto M, Rosado-Alvarez D, Gómez-Garduño A, et al. (2013) Mediterranean diet, moderate-tohigh intensity training, and health-related quality of life in adults with metabolic syndrome. European journal of preventive cardiology 20(4): 555-564.

19. Paletas K, Athanasiadou E,Sarigianni M, Paschos P, Kalogirou A, et al. (2010)"The protective role of the Mediterranean diet on the prevalence of metabolic syndrome in a population of Greek obese subjects." Journal of the American College of Nutrition 29(1): 41-45.

20. Babio N, Bullo M,Basora J, Martínez-González MA, Fernández-Ballart J, et al. (2009) Adherence to the Mediterranean diet and risk of metabolic syndrome and its components. Nutrition, metabolism and cardiovascular diseases 19(8): 563-570. 
21. (2001) National Heart Lung and Blooc Institute (2001) Executive Summary of The Third Report of The National Cholesterol Education Program (NCEP) Expert Panel on Detection, Evaluation, And Treatment of High Blood Cholesterol In Adults (Adult Treatment Panel III). JAMA285(19): 2486-2497.

This work is licensed under Creative Commons Attribution 4.0 License

Submission Link: https://biomedres.us/submit-manuscript.php
22. Pasha E P, Birdsill AC,Oleson S, Haley AP, Tanaka H(2018) Physical activity mitigates adverse effect of metabolic syndrome on vessels and brain. Brain imaging and behavior: 1-11.

23. RikliR E, Jones CJ (2001) Senior fitness test manual. Champaign, IllLeeds: Human Kinetics. 